Journal of Maternal and Child Health (2019), 4(5): 342-350

https://doi.org/10.26911/thejmch.2019.04.05.07

\title{
Maternal Mortality Evaluation: A Case Study in Bantul, Yogyakarta
}

\author{
Arlina Dewi'), Nikma Kurnianingtyas Bekti'), Supriyatiningsih²) \\ 1)Masters Program in Hospital Management, Universitas Muhammadiyah Yogyakarta \\ 2)Department of Obstetrics and Gynecology, Faculty of Medicine and Health Science, \\ Universitas Muhammadiyah Yogyakarta
}

\begin{abstract}
Background: Maternal mortality rate is one of the indicators to measure the level of a woman's health. The maternal mortality rate in Indonesia is still high, it's about 190/100.000 live birth. The objective of the present study is to evaluate the cause of maternal death in Bantul at 2016 which related to the health services including human resources.

Subjects and Method: This was a mixed method with case study design on maternal mortality in Bantul District. The qualitative data collected through Focus Group Discussion (FGD) and the quantitative data from the questionnaire were filled by a senior midwife throughout the hospital in Bantul. The number of hospitals in Bantul District was 11 consisting of 1 government hospital and 10 private hospitals.

Results: The number of obstetricians who could be available 24 hours in hospitals was still limited. The skills of midwives were still considered to be limited in handling a number of obstetric emergency conditions due to the lack of regular training. The primary health care services which had been provided to support and handle obstetric emergencies, but the infrastructure and human resources were still considered inadequate. Thus, there was also a condition where the utilization of integrated ANC facilities in the primary health center (Puskesmas) was still low, soan early detection of complications of pregnancy was less optimal.

Conclusion: There are three main topics causing the maternal mortality at Bantul, and those are 1)Maternal mortality related to hospital facilities, 2) Maternal mortality related to human resources at the hospital, 3) Maternal mortality related to health center facility.
\end{abstract}

Keywords: maternal, obstetrician stand-by, hospital

\section{Correspondence:}

Arlina Dewi. Masters Program in Hospital Management, Universitas Muhammadiyah Yogyakarta. Jl. Brawijaya, Bantul 55183, Yogyakarta, Indonesia. Email: dewikoen@yahoo.com. Mobile: +628122972576

\section{BACKGROUND}

Maternal mortality rate (MMR) is a health problem that is one of WHO focuses. Every day, it is estimated that 830 women die due to the causes related to pregnancy and birth.

In 2015, approximately 303,000 women died. Ninety-nine percent of maternal deaths occur in developing countries. Indonesia is one of the developing countries which need attention to maternal mortality. In 2015, MMR in Indonesia has not been able to reach the MDGs target which is still 190/100,000 live births while the MDGs target is 102/100,000 live births (WHO et al., 2015).

Based on the maternal mortality data from Yogyakarta health office in 2015, it was found that in the city of Yogyakarta, there were 2 cases, and Bantul Regency had 11 cases. Besides, Kulonprogo Regency had 2 cases, Sleman Regency had 4 cases. Gunungkidul District had 2 cases as well. Hence, Bantul Regency occupied the top 
position in the Special Province of Yogyakarta (Dinkes DIY, 2015).

The results of the Maternal Perinatal Audit (MPA) concluded that the causes of maternal deaths in 2015 were severe preeclampsia (SPE), 36\% (4 cases), bleeding by $36 \%$ ( 4 cases), pulmonary TB $18 \%$ ( 2 cases), and amniotic emboli $9 \%$ ( 1 case). The spread cases of maternal deaths in Bantul regency occurred in several sub-districts with the highest number of cases reported in the Sedayu II Health Center, Banguntapan I, and Jetis I with 2 cases (Dinkes Bantul, 2017). In addition, the maternal death audit used 112 medical records conducted by the Indonesian Obstetrics and Gynecology Association in November 2014 which divided the causes of maternal deaths in 3 major groups namely: 1) General condition, 2) Pre-hospital role, and 3) Hospital role (Saleh, 2014).

\section{SUBJECTS AND METHOD}

This was a mixed method study with case studies on maternal mortality in Bantul Regency. Qualitative data were obtained from the Focus Group Discussion (FGD), and quantitative data used a questionnaire as a research instrument. The number of hospitals in Bantul Regency is 11 consisting of 1 government hospital and 10 private hospitals. Likewise, the study population for qualitative data involved all midwives, obstetricians, and health department staffs.

Moreover, Bantul Regency which is directly related to maternal health services. In the quantitative population data, those included all midwives who work in Bantul Regency hospitals. Besides, qualitative data samples were the participants consisting of senior midwives or maternity room coordinators who worked in hospitals as obstetricians and gynecology specialists as well as representatives from District and Provincial Health Offices related to maternal health services in Bantul Regency. A sampling of qualitative data was selected by purposive sampling method. The informant had been determined by a researcher consisting of all senior midwives at Bantul Regency hospital. Therefore, quantitative data samples were chosen by representatives of a senior midwife or maternity room coordinator in each hospital in Bantul regency.

\section{RESULTS}

The FGD results were categorized into 3 groups namely 1) hospital facilities related to maternal deaths, 2) maternal mortality rates related to human resources in hospitals, 3) maternal deaths related to primary health care. For more detailed information, each result is explained in the following paragraphs.

\section{Maternal mortality Related to Hospital Facilities}

Hospitals as advanced health facilities should have the readiness facilities and infrastructures which support the services for pregnant women, especially who are referred to special condition or emergency condition.

A representative of obstetrician stated that there were several conditions of the hospitals which were not in accordance with the hospital standards:

"Well, if we take a look at some explanations of the people who have contributed into maternal mortality cases, evidently, there have not been sophisticated tools in accordance to hospital facilities, availability of operating rooms, and availability of doctors."

Bantul district health office also added about the conditions in Bantul where all cases of death occurred at the hospital. The statement mentioned was likely related to available ICU room and foundation management at the hospital: 
"Indeed, from 12 deaths, we evaluated that some deaths occurred in a secondary health facility or at the hospitals. Regarding the possible existence of ICU rooms and foundation management in the health facilities, we cannot deny that there are still people who access un-PONEK hospitals directly. "

In regards to the audit results submitted by representatives of the Yogyakarta Health Office, it was obtained from 12 cases of maternal deaths in 2016, three cases occurred in government hospitals, two cases in central hospitals, and the rest of the cases occurred in private hospitals. Therefore, it was necessary to pay more attention to private hospitals. Also, the statements mentioned were supported by the statement below.

"If we pointed out to Bantul regarding the maternal deaths in 2016, the maternal deaths also occurred at all hospitals. For the season, it turned out that this private hospital also contributed to helping the maternal deaths. Besides, from 12 cases happened in Bantul especially in a regional hospital, there included only 3 cases of maternal deaths. Also, at central hospital, there were two cases of maternal deaths happened. Thus, the existence of private hospitals had to be given more attention as well."

\section{Maternal Mortality Related to Human Resources at the Hospital}

One of the conditions associated with human resources in a hospital was about an obstetrician's dilemma when facing certain emergency cases. The dilemma was related to decision making to take immediate action. Thus, an obstetrician representative conveyed his experience:

"One of taking the decisions is about the system which can be done in order to get results for very severe cases which do not stand alone. Perhaps, it could be with other Obstetricians or a suggestion or a mechanism where if there was something that really needed to be done, it included quite a risky action. Also, there was a symbiosis of suggestions from other obstetricians which might not be available at this time."

In addition, existing human resources also needed to get updated knowledge regularly only if it was needed especially for personal evaluation. In line with what was stated by other obstetrician representatives who argued:

"From the study, it was mentioned that 53\% of patients experienced improper clinical decision making which was quite high. From the case mentioned, it needed to be evaluated and it also included $47 \%$ of late execution personally. "

Yogyakarta provincial health office also added the conditions when there was a referral to a hospital, not all referral cases were handled by an obstetrician. Some references were still handled by hospital midwives as stated below:

"Evidently, this hospital also had a lot of cases in regards to the limited human resources of doctors, especially for specialists, so if there was a reference, it turned out that there was also an existing midwife. Then, the one who helped or provided the first treatment or even the midwife would be clear in consultation or telephoning."

In addition, there were also problems regarding the periodic training for midwives which were rarely carried out due to constrained costs. Most of the people who attended the training were only to fulfill the registration certificate extension requirements. Some hospitals facilitated funding for midwifery training, but many of them also did not facilitate medical staffs because they considered the training to be a private 
investment of a midwife, not related to the hospital:

"Midwives also have a kind of periodic training, and they should do the training in order to courage their abilities increased, sharpened, and reminded. For the problem, I ask midwives training, and they say it is expensive. Well, nurses have the same assumption too. In fact, the training is expensive which sometimes it does not participate in training as well, or sometimes, the training is very tight when they have to extend the registration certificate. Besides, some hospitals facilitate to allocate funds for this training. However, most hospitals are unwilling because they might be considered as their own needs. As same as the obstetrician, every 5 years, the registration certificate must be followed up regarding the for permission practice license extension in renewing the registration certificate. Therefore, they have to pay for it their selves, but maybe, for some midwives; it might still be an obstacle."

\section{Maternal Mortality Related to Primary Health Care}

Bantul regency has 8 PONED health centers and 16 health centers hospitalized to facilitate first-level health services. However, it is still constrained by limited human resources and physical infrastructure. As stated by representatives of the Bantul District Health Office, they said that:

"For the health centers related to maternal handling readiness, we prepared 8 PONED health centers and 16 health centers inpatient car. Then, all of them still experienced possible limitations in terms of human resources. For the limitation related to physical infrastructure, we strived to always propose at the district level which was expected to be able to meet the needs related to physical infrastructure and medical devices for maternal handling."
Representatives of obstetricians focused on the stabilization of pre-referrals and communication between referrers and health workers in the referral hospital:

"Not only one person who had a title of Sp. OG had to work, but also from the beginning, if we had already known about it, we thought at first level health or in health care provider (PPK 1), we had all the warnings. Now only we want to not obey the warning. All of them are already at high risk, so from the beginning, a consultation conducted. Also, it should include well-evaluated in order not to get an emergency to the women. Well, in my opinion, there must be good communication from the leader to the staffs of health providers."

An obstetrician representative also added about the situation of patients who had never performed ANC to a first-rate health facility, so they were not immediately referred to secondary health facilities:

"I have also met a number of patients whose actual risk factors should have been detected beforehand, but the patient was never referred to at least get an ANC consultation in our place so that it seemed suddenly. Also, the condition was not good even though it was actually a series of several weeks earlier. "

Representatives from one of the health center highlighted the importance of implementing integrated ANC at the health center. Recently, some pregnant women preferred to go directly to the hospital or to an independent practice doctor even though there were not including integrated ANC provision facilities except the health center.

"All pregnant women should be contacted to the health center especially for monitoring the local area. Secondly, it should get integrated ANC. Then, I have to convey the integrated ANC to the mother 
in Bantul in which the integrated ANC is required by the health center. For the first handling of patients, they should be contacted by a general practitioner for screening the disease. For the second step, the patients must be contacted by the dentist at the health center. This is why after all if you have the patients, you should bring them to the health center based on their needs. Also, if the patients have a nutritional problem, they should be brought to nutrition experts as well."

Table 1. Maternal Mortality in Bantul Regency

\begin{tabular}{|c|c|c|c|}
\hline \multirow{2}{*}{ Hospital Types } & \multicolumn{3}{|c|}{ Year } \\
\hline & 2014 & & 2016 \\
\hline B (1 RS) & 3 & 4 & 3 \\
\hline $\mathrm{C}(2 \mathrm{RS})$ & 2 & 2 & 1 \\
\hline $\mathrm{D}(6 \mathrm{RS})$ & 0 & 0 & 1 \\
\hline Total & 5 & 6 & 5 \\
\hline
\end{tabular}

Table 2. Questionnaire Data to Support the Facilities of Pregnant Women Health Services in Hospital

\begin{tabular}{llll}
\hline \multirow{2}{*}{ Parameter } & \multicolumn{3}{c}{ Hospital Types } \\
\cline { 2 - 4 } & $\mathbf{B ~ ( n = 1 )}$ & $\mathbf{C}(\mathbf{n}=\mathbf{2})$ & $\mathbf{D}(\mathbf{n}=\mathbf{6})$ \\
\hline $\begin{array}{l}\text { Anesthetic equipment, operating room, 24-hour } \\
\text { Standby surgical equipment }\end{array}$ & 1 & 2 & 6 \\
$\begin{array}{l}\text { Baby resuscitation equipment } \\
\text { Active management equipment 3 }\end{array}$ & 1 & 2 & 4 \\
$\begin{array}{l}\text { Equipment for obstetric emergencies in the emergency } \\
\text { room }\end{array}$ & 1 & 2 & 6 \\
Obstetric emergency equipment in the delivery room & 1 & 2 & 6 \\
Obstetric emergency medicine at emergency room & 1 & 2 & 5 \\
Obstetric emergency medicine in the delivery room & 1 & 2 & 6 \\
\hline
\end{tabular}

Table 3. Human Resource Questionnaire Data Related to the Care and Treatment of Pregnant Women at Hospital

\begin{tabular}{|c|c|c|c|}
\hline \multirow{2}{*}{ Parameter } & \multicolumn{3}{|c|}{ Hospital Types } \\
\hline & B $(n=1)$ & $C(n=2)$ & $D(n=6)$ \\
\hline Standing-by Obstetrician in 24 hours & 1 & 2 & 3 \\
\hline $\begin{array}{l}\text { The operating team with the operating assistant / } \\
\text { 24-hour standby surgical nurse team }\end{array}$ & 1 & 2 & 5 \\
\hline $\begin{array}{l}\text { The operation team with a } 24 \text {-hour standby } \\
\text { specialist }\end{array}$ & 1 & 1 & 1 \\
\hline $\begin{array}{l}\text { The emergency doctor with obstetric emergency } \\
\text { competency }\end{array}$ & 1 & 2 & 3 \\
\hline
\end{tabular}

\section{DISCUSSION}

In regards to The Tenth Revision of International Classes of Diseases (ICD-1O), the maternal mortality occurs during pregnancy or in 42 days after the end of pregnancy, regardless of the length and location of pregnancy, caused by anything related to pregnancy, or aggravated by pregnancy or in the handling. Besides, maternal mortality is not caused by an accident(Say et al., 2014). In addition, there are several risk factors which can influence maternal mortality, and one of them is related to the non-medical factors and health services (Arulita, 2007). 
Hospital facilities as a place of reference should meet minimum standards. However, at some referral hospitals, this has not yet been fulfilled. Meanwhile, in Bantul regency, there is only a hospital which has been certified as a PONEK hospital. For un-PONEK hospitals, many of which are still constrained by the absence of obstetricians who stand-by for 24 hours. Powell explained that on his study, good hospital infrastructures can be one of the keys in decreasing maternal mortality.

In this national health insurance $(\mathrm{JKN})$ era, the facilities and infrastructure in the referral hospital are deemed unable to respond to the surge in referrals. The multilevel referral system only allows referring to a higher type of hospital. Meanwhile, number A and B hospitals are still a limited number. In addition, to the limited number, not all referral hospitals have the facilities for handling obstetric emergencies. From the statement mentioned, it is caused by the determination of hospitals that were only based on the minimum number of beds and are not based on more important considerations such as ICU, NICU facilities, ventilators, or other health equipment. There are some hospitals which have fulfilled the latest and more needed medical equipment requirements, but they are still classified as class $\mathrm{C}$ hospitals (lower classes) because they do not meet the minimum number of beds. As a result, the hospital may not serve labor complications which are quite severe (Noerdin et al., 2015).

The existence of health workers who are competent in the obstetrics field is one of the things which become highly prioritized in pregnant women services. In fact, in reality, there are still many shortcomings in terms of quantity and quality. In the previous study, it was found that one of the lack of health providers quantity is an uneven distribution of health workers (Sousa et al., 2006; Speybroec et al., 2012). The previous research was also in line with Bossert et al. (1991) who said that uneven distribution of health workers becomes a serious problem in medical health world.

Efendi (2012) explained that in his research, it related to the provision of health workers in remote areas in Indonesia. Government programs in the form of contract workers and special assignments showed a significant contribution to increasing the availability of health workers.

Apart from the unequal distribution of health personnel problems, there are several other things which cause problems in the human resource aspect. The low salaries of existing health workers, poor working conditions, lack of supervision, and lack of infrastructure also influence human resource problems (Ferrinho et al., 1999; Kirigia et al., 2006; Lehmann et al., 2008; Ramani et al., 2013).

Additionally, regular training for midwives is also a concern focus in order to reduce maternal mortality. The limited number of obstetricians who stand by for 24 hours at a hospital has resulted in hospital midwives needing to improve and always update their skills in handling emergencies in pregnant women. In several studies, it was found that the availability of trained midwives showed a significant reduction in maternal mortality (Campbell et al., 2006; Wilson et al., 2011).

The health system in Indonesia which uses a multilevel referral system makes primary health facilities as the main gateway for the community as well as in the service and handling of pregnant women. However, from the FGD results, it was found that some conditions were not ideal. One of them was the lack of attention from the health center on ANC discipline of pregnant women which caused when a 
condition required a referral as if the patient "suddenly" came in a bad condition. Yego et al. (2014) mentioned that in his study, ANC is really needed by the pregnant women since it can be very helpful in identifying the risk factors in order to prevent maternal mortality.

In addition, there are also shortcomings in the aspects of human resources and infrastructure in the health center. Besides, this condition can be seen in the basic data of DIY health center in 2015 where there were several health centers which had not yet become PONED health centers and also lack of midwife staffs (Kemenkes, 2015).

Taking a look at the conditions at the health center, it is necessary to have better monitor compliance with Standard Operating Procedure (SOP) and the applicable guidelines. The use of SOP and updated guidelines can help to improve the community service. In addition, health workers at the health center are also expected to understand well and also have initiatives related to services provided in accordance with the guidelines (Mashalla et al., 2016).

Moreover, some pregnant women also choose to come to the hospital and health center. Regarding the research conducted by Emelumadu et al. (2014), this is possible that the services in the hospital are more comfortable, and there are specialist doctors. Also, the hospitals are easily accessible. In some previous studies, it was found that pregnant women prefer to come to health facilities which have more complete health workers although some pregnant women in rural areas still use traditional midwives services (Hutchinson et al., 2011; Osubor et al., 2006; Uzochukwu et al., 2004).

\section{CONCLUSION}

Available facilities and infrastructure do not meet the specified standards. The number of obstetricians who can stand-by 24 hours in hospitals is still limited. Besides, there are conditions where many referrals to hospitals are also not directly handled by obstetricians, but they are handled by hospital midwives. Meanwhile, the skills of midwives are still considered to be limited in handling a number of obstetric emergency conditions due to the lack of regular training.

There have already included several PONED health centers to facilitate health services for pregnant women, but infrastructure and human resources are still considered inadequate. Regarding the referral system, good communication between referrers and health workers in referral hospitals is one of the important things which play a role in reducing the risk of referral to pregnant women. Another thing that also needs to be considered is the lack of utilization of integrated ANC facileties in the health center. Therefore, early detection of complications of pregnancy is less optimal.

\section{REFERENCES}

Arulita F (2007). Faktor-Faktor Risiko yang Mempengaruhi Kematian Maternal (Studi Kasus di Kabupaten Cilacap) (PhD Thesis). Tesis, Program Studi Magister Epidemiologi, Program Pasca Sarjana Universitas Diponegoro, Semarang.

Bossert T, Soebekti R, Rai NK (1991). Bottom-up' planning in Indonesia: decentralization in the ministry of health. Health Policy Plan. 6: 55-63. https://doi.org/10.1093/heapol/6.1.5 5 .

Campbell OM, Graham WJ (2006). Strategies for reducing maternal mortality: 
getting on with what works. The Lancet. 368: 1284-1299.

Dinkes Bantul (2017). Profil Kesehatan Kabupaten Bantul 2016.

Dinkes DIY (2015). Narasi Profil Daerah Istimewa Yogyakarta.

Efendi F (2012). Health Worker Recruitment and Deployment in Remote Areas of Indonesia (SSRN Scholarly Paper No. ID 2884694). Social Science Research Network, Rochester, NY.

Emelumadu OF, Onyeonoro UU, Ukegbu AU, Ezeama NN, Ifeadike CO, Okezie OK (2014). Perception of quality of maternal healthcare services among women utilizing antenatal services in selected primary health facilities in Anambra State, Southeast Nigeria. Niger. Med. J. J. Niger. Med. Assoc. $55,148$.

Ferrinho P, Van Lerberghe W, da Cruz Gomes A (1999). Public and private practice: a balancing act for health staff. Bull. World Health Organ.

Hutchinson PL, Do M, Agha S (2011). Measuring client satisfaction and the quality of family planning services: a comparative analysis of public and private health facilities in Tanzania, Kenya, and Ghana. BMC Health Serv. Res. 11, 203. https://doi.org/10.1186/1472-6963-11-203.

Kemenkes (2015). Data Dasar Puskesmas DIY 2015.

Kirigia JM, Gbary AR, Muthuri LK, Nyoni J, Seddoh A (2006). The cost of health professionals' brain drain in Kenya. BMC Health Serv. Res. 6, 89.

Lehmann U, Dieleman M, Martineau T, (2008). Staffing remote rural areas in middle-and low-income countries: A literature review of attraction and retention. BMC Health Serv. Res. 8, 19.
Mashalla YJ, Sepako E, Setlhare V, Chuma M, Bulang M, Massele AY (2016). Availability of guidelines and policy documents for enhancing performance of practitioners at the Primary Health Care (PHC) facilities in Gaborone, Tlokweng and Mogoditshane, Republic of Botswana. J. Public Health Epidemiol. 8, 127-135.

Noerdin E, Aripurnami S, Anindhita F, Elison NK, Pelangi B, Susanti LR, (2015). Pemenuhan Fasilitas Kesehatan Ibu Melahirkan Era Jaminan Kesehatan Nasional.

Osubor KM, Fatusi AO, Chiwuzie JC (2006). Maternal health-seeking behavior and associated factors in a rural Nigerian community. Matern. Child Health J. 10, 159-169. https://doi.org/10.1007/s10995-005-0037-z

Powell-Jackson T, Gao Y, Ronsmans C, Zhou H, Wang Y, Fang H (2015). Health-system determinants of declines in maternal mortality in China between 1996 and 2013: a provincial econometric analysis. The Lancet, The Lancet-CAMS Health Summit Abstracts booklet 386, S15. https://doi.org/10.1016/So140-6736(15)oo593-o

Ramani S, Rao KD, Ryan M, Vujicic M, Berman P (2013). For more than love or money: attitudes of student and inservice health workers towards rural service in India. Hum Resour Health. 11: 58. doi: 10.1186/1478-4491-11-58.

Saleh N (2014). Audit Kematian Ibu.

Say L, Chou D, Gemmill A, Tunçalp Ö, Moller AB, Daniels J, Gülmezoglu AM, Temmerman M, Alkema L (2014). Global causes of maternal death: a WHO systematic analysis. Lancet Glob. Health 2: e323-e333.

Sousa A, Tandon A, Dal Poz MR, Prasad A (2006). Measuring the efficiency of human resources for health for attain- 
ing health outcomes across subnational units in Brazil. World Health Organization.

Speybroeck N, Paraje G, Prasad A, Goovaerts P, Ebener S, Evans DB (2012). Inequality in Human Resources for Health: Measurement Issues. Geogr. Anal. 44, 151-161. https://doi.org/10.1111/j.1538-4632.2012.00842.x

Uzochukwu BSC, Onwujekwe OE, Akpala CO (2004). Community satisfaction with the quality of maternal and child health services in southeast Nigeria. East Afr. Med. J. 81: 293-299.

WHO, UNICEF, UNFPA, World Bank Group (2015). Trends in maternal mortality: 1990-2015: estimates from
WHO, UNICEF, UNFPA, World Bank Group and the United Nations Population Division.

Wilson A, Gallos ID, Plana N, Lissauer D, Khan KS, Zamora J, MacArthur C, Coomarasamy A (2011). Effectiveness of strategies incorporating training and support of traditional birth attendants on perinatal and maternal mortality: meta-analysis. BMJ. 343: d7102. https://doi.org/10.1136/bmj.d 7102

Yego F, D'Este C, Byles J, Williams JS, Nyongesa P (2014). Risk factors for maternal mortality in a Tertiary Hospital in Kenya: a case control study. BMC Pregnancy Childbirth 14: 38. 